Virtual Mentor. March 2003, Volume 5, Number 3.

doi: 10.1001/virtualmentor.2003.5.3.ccas2-0303

Clinical Cases

\title{
An Impaired Resident
}

\section{Physicians and physicians-in-training have a responsibility to speak up if they feel a medical colleague's impairment puts patients at risk.}

\author{
Commentary by Erin Egan, MD, JD, and Dewitt C. Baldwin Jr., MD
}

Stevenand John are second-year residents in internal medicine at a major urbanhospital. They have been friends since medical school and became closerwhile sharing long shifts during their intern year.

Overthe past few weeks, John has not been himself. Steve thinks John has lookedmore sleep-deprived than the usual resident does, and that he might evenappear tearful at times. John hasn't been joining the other residentsfor lunch and, when he does, Steve notices that he doesn't eat verymuch. Concerned, Steve realizes that John has been somewhat withdrawn forseveral months now. Previously, John, Steve, and Steve's wife Mariaoften went out to dinner or got together in the evenings, but John has declinedthe past few invitations. Steve has been passing off John's new behavioras the "winter blues" combined with the normal ups and downs of residencytraining. The R2s have been working as many hours as they did as interns,so Steve didn't make a big deal out of the fact that John didn'thave time to hang out.

Lastweek, Steve saw the normally friendly and even-keeled John growl at a medicalstudent and then yell at a nurse on the unit. Afterwards, he heard the nursescomplain that John seemed distracted, hard to locate sometimes when theyneeded him, and had yelled at them about some missing lab results when itwas he who had forgotten to order them in the first place. John had alsobeen asking them for the correct dosages of commonly prescribed medications.In fact, John's behavior seemed so unpredictable and difficult oflate that one nurse on the unit was asking for a transfer.

WhenSteve asked John whether everything was okay, John replied, "Yeah, fine."When Steve pressed a little about John's mood, John became defensive."What, I'm supposed to be cheerful, too? Just because I'm nothere 15 minutes before everyone else, and I ask some questions before chargingahead with treatment, suddenly the attending is all, 'You'd better shape up, Dr. Masterson.' Whatever."

Stevebegan thinking John must be depressed, or at least that John shouldtalk to someone about his dissatisfaction with how things were going. Sincehe had been ignoring his friends, Steve wondered how willing John wouldbe to accept help. Steve even found himself worrying about John'spatients.

Onthe other hand, Steve thought that he might be making too much of what wasjust a bad mood. And he worried about the potential harm he could do toJohn's career by mentioning the situation to the residency director.Steve had heard that state medical boards require psychiatrists to turnover records of doctors whom they saw as patients. He also thought aboutthe negative image many in the hospital had of mental illness (or any weaknessin general) among residents. He didn't want to paint John as deficientjust because he had a bad week.

Finally,Steve brought up the topic with Chris, another resident, and a mutual friendof his and John's. Chris said, "Oh, man, I wouldn't touch thatwith a ten-foot pole."

"Ifhe was drinking or doing drugs, would you do something?" Steve asked.

"Yeah,but there's a difference." 
"What'sthe difference?" asked Steve. "He's actin' weird. He'smaking mistakes. You want to wait til someone gets hurt? What if John getshurt?

"Yeah,but if you label him as a psych case, he'll never get a job. Hell,he may not get a license."

"Andif he screws up and causes harm to somebody?"

Chrisdid not respond. Great. Steve was more confused than before.

\title{
Commentary 1
}

\author{
by Erin Egan, MD, JD
}

Residencyis a time of physical, emotional, financial, and intellectual stress. Eachresident reacts differently, but all experience times when their reactionsto the stress affect their behavior. The emotional and cognitive behaviordisturbances that occur in residency have been well-documented. Residentsreport mood swings, appetite disturbances, depression, and increasing cynicism[1]. They frequently report feeling burned outand admit that this emotional state affects the patient care they provide[2]. Sleep deprivation is increasingly recognizedas a cause of impairment and error [3]. All ofthis indicates that residents (and almost everyone else) are regularly expectedto perform their clinical duties with some degree of impairment at leastsome of the time. It is hard to say when an individual resident has crossedthe line from the normal reaction to residency training to being dangerouslyimpaired.

Physicianshave a duty to report impaired or incompetent physicians. This duty is reflectedin professional codes of ethics and is reinforced in medical ethics training[4,5]. However, beyond impairmentdue to substance abuse, there is little guidance as to what constitutesimpairment or incompetence. Deciding when another resident is dangerouslyimpaired is a difficult call, largely left to the judgment and conscienceof each physician. Residents already have anxiety about their clinical decision-makingskills and responsibility, and making this type of judgment about a colleaguecan be overwhelming. On the other hand, it is essential that residents bewilling to take proper ethical action when the behavior of a colleague becomesalarming. Because residents work together and depend upon one another, theywill be the first to notice problems in other residents' clinicalperformance. Residents are therefore the first warning mechanism when patientsafety is threatened by a resident's impairment.

Patientsafety is the crucial issue. Issues of professionalism are extremely important,and if a resident is behaving inappropriately toward other providers orancillary staff some action must be taken. But when patient safety is atissue the problem takes on a special urgency.

Thefirst step in determining what to do in this month's clinical caserequires that Steve decide whether he believes John's behavior isa threat to patient care. If so, then Steve has no choice but to go to theprogram director immediately. The fact that Steve is aware of specific instancesof errors and omissions probably means that there are many instances thathe is not aware of. As painful as it is, and regardless of the possibleeffect of John's career, if patients are even possibly at risk, thereis no excuse for any delay.

Ifpatient safety is not immediately threatened, Steve has time to look ata few other options. Getting feedback from others is helpful. It may helpSteve feel more comfortable that he is doing the right thing, and it mayopen up options that Steve had not previously considered. There may be residentsupport services at the hospital, or a counselor that John can talk to.Chief residents are also a resource for this type of conflict.

Oneconcern that Steve has is that John's career may be affected. Thereare 2 perspectives on this that may help. First of all, John's careermay be enhanced if he needs help and gets it now. Certainly John will havebetter career options if he is not seen as difficult to work with and unprofessional.In addition it is unlikely that John's career would be affected byalerting the program director to the problem. Most programs understand thatresidents are under a huge amount of stress, and that other aspects of aresident's life may make that stress temporarily unbearable. Programdirectors have avenues to deal with these kinds of problems that have nolong-term effect on a resident's career. If Steve waits until othersreport John's behavior, early interventions may no longer be available.Steve may best protect John's career by 
alerting the people who arein a position to help John.

Residencytraining is a difficult time. Every resident will experience some degreeof impairment due to stress or sleep deprivation. Other residents are animportant support system when stress becomes overwhelming. Sometimes problemsare severe enough that additional action must be taken. When those situationsarise, residents must act to protect patients' welfare. Ultimatelythe decision to intervene is matter of conscience and personal integrity.These problems are present at all levels of medical practice and they donot become any easier to address. The ethical duty to report impaired colleaguesis part of the price of being a professional, and the duty is to patients,not colleagues or friends.

\section{References}

1. Cefalo RC. Stress in medical residency: status quo after a decade of reform? Obstetrical and Gynecological Survey. 2002;57:496-497. View Article PubMed Google Scholar

2. Shanafelt TD, Bradley KA, Wipf JE, Back AL. Burnout and self-reported patient care in an internal medicine residency program. Ann Intern Med. 2002;136:358-367.

View Article PubMed Google Scholar

View Article PubMed Google Scholar

3. Weinger MB, Ancoli-Israel S. Sleep deprivation and clinical performance. JAMA. 2002;287:955-957. View Article PubMed Google Scholar

4. AMA Council on Ethical and Judicial Affairs. Reporting impaired, incompetent, or unethical colleagues, E9.031. Code of Medical Ethics. Accessed August 29, 2002.

5. Synder L, Morin K, eds. Ethics Manual. 4th Ed. Philadelphia: American College of Physicians; 2000.

Erin Egan, MD, JD, is a senior associate at the Neiswanger Institute for Bioethics and Health Policy at the Stritch School of Medicine at Loyola University, Chicago and a resident in the Department of Internal Medicine, Loyola University Medical Center.

\section{Commentary 2}

by DeWitt C. Baldwin Jr, MD

There are 4 basic questions here.

1. What is going on with John?

2. What is causing it?

3. How aberrant is it?

4. What can/should Steve (or others) do about it?

Is John behaving in an impaired manner? Of course he is! His friends and fellow residents, Steve and Chris, as well as the nurses and medical students have all noted and even commented on it. And it will probably not be long before his attendings become aware of it, if they are not already. Is it unusual? From what we are told, it seems to be unusual for him. He simply is not behaving the way he usually does both at work and away from work.

Is such impaired behavior unusual among sleep-deprived and overworked residents? Not at all! Over half of the PGY1 and PGY2 residents in a recent national survey reported that they had worked at least once during the past year while in an "impaired condition," ascribing it largely to sleep loss and overwork [1].

Should we be concerned about his behavior? Absolutely! If he continues to do the things he is doing, the care of his 
patients is going to suffer and the chances of a medical mistake appear likely. Steve's concern for his friend and colleague is well founded. And even Chris knows that John is heading for trouble, but is fearful of the traditional "marine corps" mentality of medicine that admits of no "weakness or failure."

But is this all that's going on? No! He is also clinically depressed. In addition to showing some of the types of impaired behavior that many residents may show under conditions of sleep deprivation and stress, he also exhibits some classical symptoms of depression: social withdrawal, loss of appetite, mood disturbances, mental distraction, sleep loss, cognitive impairment, and emotional outbursts that are not typical of him.

Is this unusual? Again, not at all! Many studies have described the serious physical, psychological, and emotional consequences of prolonged sleep deprivation, fatigue, and stress during residency [1]. In one report, more than 30 percent of residents were found to be clinically depressed during their first post-graduate year [2]. In the past, many such residents simply "toughed it out" or self-medicated.

What should/can Steve (or others) do? Since the situation appears to be deteriorating and clinical depression is eminently treatable, it would seem to be a friendly and collegial act to assist John to get some relief from the symptoms that must surely be disturbing to him as well. Indeed, not reporting behavior of a colleague that could potentially result in harm to a patient is unethical, since it violates the fundamental fiduciary responsibility of physicians to their patients. Allowing John to continue to "screw up" clinically also is unfair to him as well as to his colleagues and patients.

While Chris may feel concerned about the possible negative professional consequences of getting help for John, most residency directors today have been sensitized to the effects of prolonged sleep deprivation and fatigue during residency, and confidential systems for referral and treatment are nearly always available without prejudice. Talking to a sympathetic and trusted faculty member, or to the program director, or even to the director of medical education in the hospital, is probably the best way to start the process if John cannot accept the fact of his impaired and potentially harmful behavior and seek help himself.

As far as stigmatizing John with a psychiatric diagnosis, his depression, while clinically real, seems fairly recent and largely situationally determined. As such, it can probably be treated as well by an experienced internist or generalist as by a psychiatrist. Since medication for depression may take a few weeks to become fully effective, a brief medical leave may be considered. However, recognition and acceptance of the problem, together with good medical treatment and collegial support, should make such a disruption unnecessary. As for Chris's concerns about how this could affect John's future licensure, since depression is frequently treated by physicians other than psychiatrists and is such a common problem among residents, I believe there is little substance to his worries about John's having a psychiatric record that would be of concern to a State Medical Board.

\section{References}

1. Shanafelt TD, Bradley KA, Wipf JE, Back AL. Burnout and self-reported patient care in an internal medicine residency program. Ann Intern Med. 2002;136:358-367.

View Article PubMed Google Scholar

View Article PubMed Google Scholar

2. Valko RJ, Clayton PJ. Depression in the internship year. Dis Nervous Sys. 1975;36:26-29. Google Scholar

DeWitt C. Baldwin Jr, MD, trained in pediatrics, psychiatry, and family medicine and has held professional rank at 9 medical schools, 2 of which he helped to start. He currently serves as scholar-in-residence at the Accreditation Council for Graduate Medical Education (ACGME), where he continues to research and write about the working and learning environment of medical students and residents.

The people and events in this case are fictional. Resemblance to real events or to names of people, living or dead, is 
entirely coincidental. The viewpoints expressed on this site are those of the authors and do not necessarily reflect the views and policies of the AMA.

(C) 2003 American Medical Association. All Rights Reserved. 